\title{
Brazilian medical publications: citation patterns for Brazilian-edited and non-Brazilian literature
}

J.R. Cunha-Melo ${ }^{1}$,

G.C. Santos ${ }^{1}$ and M.V. Andrade ${ }^{2}$
${ }^{1}$ Departamento de Cirurgia, ${ }^{2}$ Departamento de Clínica Médica, Faculdade de Medicina, Universidade Federal de Minas Gerais, Belo Horizonte, MG, Brasil

\section{Correspondence \\ J.R. Cunha-Melo \\ Rua Groenlândia, 212/1001 \\ 30320-060 Belo Horizonte, MG \\ Brasil \\ Fax: +55-31-3248-9675 \\ E-mail: jrcmelo@medicina.ufmg.br \\ Research supported by CNPq (No. 350899/91-6). G.C. Santos is the recipient of a PIBIC CNPq fellowship (No. 108996/2004-2). M.V. Andrade is supported by NIH Grant R01 TW 00612 (GRIP).}

Received January 21, 2005 Accepted January 31, 2006

\begin{abstract}
Today, the quality of a scientific article depends on the periodical in which it is published and on the number of times the article is cited in the literature. In Brazil, the criteria for the evaluation of this scientific production are improving. However, there is still some resistance, with authors arguing that Brazilian publications must be preferentially addressed to the national readers and, therefore, they should ideally be written in Portuguese. In order to determine the kind of scientific journals cited in the reference lists of articles published in medical periodicals edited in Brazil, in the present study we determine the rate of Portuguese/English citations. Three issues of 43 periodicals (19 indexed in SciELO, 10 in PubMed, 10 in LILACS, and 4 in the ISIThompson base) of different medical specialties were analyzed, and the number of both Portuguese and English citations in the reference list of each article was recorded. The results showed that in Brazilianedited journals the mean number of citations/article was $20.9 \pm 6.9$ and the percentage of citations of international non-Brazilian periodicals was $86.0 \pm 11.2 \%$. Of the latter, $94.4 \pm 7.0$ are indexed by ISIThompson. Therefore, we conclude that Brazilian medical scientists cite the international non-Brazilian periodicals more than the national journals, and most of the cited papers are indexed by ISI-Thompson.
\end{abstract}

Several renowned biomedical journals such as Zentralblatt für Bakteriologie (Germany), Journal of Antibiotics (Japan) and Research in Immunology (France), the former Annales de l'Institut Pasteur, are now published in English (1). One of the largest bibliographic database, MEDLINE, covering the fields of medicine, nursing, dentistry, veterinary medicine, the health care system, and the preclinical sciences, contains bibliographic citations and abstracts from more than 4,800 biomedical journals published in
Key words

- Brazilian medical journals

- Bibliometrics

- Citation patterns

- Brazilian scientific journals the United States and 70 other countries. The database contains over 12 million citations dating back to the mid-1960's. Coverage is worldwide, but most records are from English-language sources or have English abstracts (2). Even for the general public interested in health science, several websites containing important information are in English. As a result, not only for scientists but also for others who want to keep up to date with the news and the developments in the biomedical field, English is the most influential sci- 
entific language.

In Brazil, many medical papers are still published in Portuguese under the assumption that the national medical community and other audiences would prefer and understand better the information in their native language, although most of the citations in periodicals edited in Brazil, even in papers written in Portuguese, are to English-language sources. This behavior has influenced generations of young scientists, with repercussions on the postgraduate medical MS and $\mathrm{PhD}$ programs in Brazil (3).

Most Brazilian physicians, if asked, could probably name a number of the most important medical journals edited in Brazil. If this question is posed to different specialists and academic MDs they would say that the most read papers are those published in periodicals edited by their National Specialty Associations. There is a common belief that Brazilian medical doctors are only able to read papers published in Brazilian journals, mainly due to language limitation. However, this may not be true. Recently, a number of Brazilian scientific journals have satisfied the requirements for indexation in SciELO. As a consequence, many of them, previously published in Portuguese, are now published in English (4). Therefore, the problem may not be simply a matter of language, but also the editorial policy for acceptance of a paper that would be more rigorous for a journal indexed in the ISI-Thompson than in the SciELO base only. Also, a small number of Brazilian scientific periodicals, although edited in Brazil, are indexed in international bases such as ISI-Thompson or PubMed, achieving an international pattern of quality. The publication of research in peer-reviewed journals is only an intermediate outcome, satisfying to authors, but not necessarily useful to others. It is not an easy task to measure how useful a published article is to clinicians. It is accepted that busy clinicians must choose carefully what reports of medical research findings to read, and in survey- ing the literature should choose publications of relevance to medical practice with methodological rigor capable of changing practice. However, we can objectively measure the impact of a paper on other authors by how frequently they cite it in their publications. Articles published in any language but English mostly share the same fate: compared to English-language papers, they are less frequently read and less frequently cited. This implies several consequences. For instance, research results published in a nonEnglish-language journal often do not reach the international scientific community, and thus systematic reviews and meta-analyses may be biased (5). Citations complete the chain of publication contributing to the evolution of scientific knowledge (6).

One of the motivations of the present article was the great influence of non-Brazilian publications observed when the reference lists of articles from Brazilian-edited medical journals are analyzed. Our hypothesis is that even if a Brazilian medical scientist prefers to submit his articles to journals published in Brazil and written in Portuguese, he more frequently cites nonBrazilian journals. The present study evaluated the percentage of non-Brazilian and Brazilian journals cited in the reference list of articles published in Brazilian medical journals. It also compared the citation pattern of these journals indexed by different databases, i.e., LILACS, SciELO, PubMed, and ISI-Thompson. The languages in which these journals are edited were determined.

Forty-three Brazilian scientific medical journals published from November 2003 to February 2004 were selected. All 33 periodicals from the SciELO database and ten additional Portuguese language periodicals, available at the Library of the Faculty of Medicine, Universidade Federal de Minas Gerais (UFMG), indexed only in LILACS and selected by a simple randomization method were analyzed. The SciELO-based journals were further divided into three 
groups: journals indexed only in SciELO, journals indexed also in MEDLINE and articles indexed also in the ISI-Thompson database. Each journal was analyzed in its higher indexed database group, avoiding duplication of the analysis of a particular periodical indexed in two or more databases. The last three issues of each journal for the period from November 2003 to February 2004 were analyzed. All citations in the reference list from all published papers of those three issues were recorded. "Editorials", "brief communications" and "case reports" were excluded. The percentage of citations of articles from non-Brazilian journals was compared to that from Brazilianedited journals in each reference list from each paper. The percentage of cited articles indexed in ISI-Thompson was also determined. A total of 1935 articles containing 34,310 citations (20.9 citations/article) were analyzed.

Medical journals published in Brazil, even if indexed in international databases, were considered in the analysis and divided into four groups: group 1) journals indexed only in LILACS ( $\mathrm{N}=10)$; group 2) journals indexed in SciELO ( $=19)$; group 3) journals indexed in SciELO and MEDLINE ( $\mathrm{N}=$ 10); group 4) journals indexed in SciELO, MEDLINE and ISI-Thompson ( $\mathrm{N}=4)$.

The percentage of average citations of Brazilian and non-Brazilian journals in the reference list of Medical journals published in Brazil was established. The languages in which these journals are published were also listed.

A list of names, mean number of articles, percentage of Brazilian and non-Brazilian citations, and percentage of non-Brazilian publications indexed in ISI-Thompson of all Brazilian medical journals studied are presented in Table 1. The number of citations/ article, the percentage of citations of Brazilian or non-Brazilian journals and the number of cited articles from journals indexed in LILACS, MEDLINE, SciELO, and ISI-
Thompson were calculated for the 43 journals examined and are shown in Table 2. The number of Journals published in each language for each database group is given in Table 3. The highest percentage of citations of non-Brazilian medical journals was found in the International Brazilian Journal of Urology (98.8\%), and the lowest (45.4\%) in the Revista Médica de Minas Gerais. The number of citations/article in the reference list ranged from 8.2/article (Jornal Brasileiro de Medicina) to 45.8/article (Arquivos Brasileiros de Endocrinologia e Metabologia). The percentage range of citations/article in a single article for ISI-Thompsonindexed journals ranged from $61.7 \%$ (Revista Brasileira de Educação Médica) to $100.0 \%$ (Jornal Brasileiro de Medicina, Revista Brasileira de Ginecologia e Obstetrícia, Revista Brasileira de Medicina, Revista Brasileira de Medicina Esportiva). The percent of non-Brazilian citations in LILACS, SciELO, MEDLINE, and ISI-Thompson was $85.5 \pm 13.9,89.8 \pm 4.5,87.8 \pm 8.2$, and 79.1 $\pm 17.1 \%$, respectively (Table 2 ). The mean \pm SD percent of international articles cited in all the Brazilian-edited medical journals was $86.0 \pm 11.2$ and the median $89.9 \%$ (Table 1).

The present results show that in Medical journals published in Brazil the percentage of citations of articles in non-Brazilian journals is significantly higher than in Brazilianedited journals. Most of the citations in Brazilian papers $(90 \%)$ are of articles published in English and predominantly from the North American scientific literature. Thus, the reader is referred to non-Brazilian journals, most of them written in English. Other countries, such as Germany are switching to the English language in order to facilitate access to research from German-speaking countries. This action seems to indicate an increase of the international dissemination of German research, at least in the psychology field (6). The same may be possibly starting to occur spontaneously in Brazil, and may represent one of the possible explanations 
Table 1. Citation data for the periodicals analyzed in the present study.

\begin{tabular}{|c|c|c|c|c|}
\hline Name & $\begin{array}{c}\text { Citations/article } \\
\text { (mean) }\end{array}$ & $\begin{array}{c}\text { Non-Brazilian } \\
\text { citations (\%) }\end{array}$ & $\begin{array}{c}\text { Brazilian citations } \\
\text { (\%) }\end{array}$ & $\begin{array}{l}\text { Citations indexed for } \\
\text { ISI-Thompson (\%) }\end{array}$ \\
\hline Acta Cirúrgica Brasileira² & 16.1 & 85.2 & 14.8 & 94.6 \\
\hline Acta Ortopédica Brasileira ${ }^{2}$ & 17.5 & 94.1 & 5.9 & 98.1 \\
\hline Anais Brasileiros de Dermatologia ${ }^{2}$ & 23.8 & 89.5 & 10.5 & 95.0 \\
\hline Arquivos Brasileiros de Cardiologia ${ }^{3}$ & 27.3 & 86.5 & 13.5 & 93.9 \\
\hline Arquivos Brasileiros de Oftalmologia ${ }^{2}$ & 14.4 & 85.1 & 14.9 & 89.7 \\
\hline Arquivos Brasileiros de Endocrinologia e Metabologia ${ }^{3}$ & 45.8 & 94.7 & 5.3 & 98.4 \\
\hline Arquivos de Gastroenterologia ${ }^{3}$ & 26.1 & 92.6 & 7.4 & 98.2 \\
\hline Arquivos de Neuro-psiquiatria ${ }^{4}$ & 20.4 & 95.1 & 4.9 & 94.9 \\
\hline Brazilian Journal of Biology ${ }^{3}$ & 18.7 & 79.8 & 20.2 & 92.4 \\
\hline Brazilian Journal of Infectious Disease ${ }^{3}$ & 20.1 & 91.6 & 8.4 & 89.8 \\
\hline Brazilian Journal of Medical and Biological Research 4 & 32.7 & 97.9 & 2.1 & 94.2 \\
\hline Cadernos de Saúde Pública ${ }^{3}$ & 16.8 & 67.8 & 32.2 & 82.2 \\
\hline Gastroenterologia e Endoscopia Digestiva ${ }^{1}$ & 21.9 & 94.8 & 5.2 & 96.8 \\
\hline International Brazilian Journal of Urology 2 & 17.7 & 98.8 & 1.2 & 99.0 \\
\hline Jornal Brasileiro de Patologia e Medicina Laboratorial2 & 19.8 & 90.9 & 9.1 & 97.5 \\
\hline Jornal Brasileiro de Medicina ${ }^{1}$ & 8.2 & 91.2 & 8.8 & 100.0 \\
\hline Jornal Brasileiro de Nefrologia ${ }^{1}$ & 23.9 & 89.2 & 10.8 & 95.7 \\
\hline Jornal de Pediatria ${ }^{2}$ & 21.6 & 87.6 & 12.4 & 99.1 \\
\hline Jornal de Pneumologia ${ }^{2}$ & 19.5 & 91.9 & 8.1 & 99.9 \\
\hline Memórias do Instituto Oswaldo Cruz ${ }^{4}$ & 21.6 & 80.9 & 19.1 & 94.7 \\
\hline Psiquiatria Biológica ${ }^{1}$ & 23.2 & 94.9 & 5.1 & 94.0 \\
\hline Radiologia Brasileira² & 16.9 & 81.7 & 18.3 & 93.6 \\
\hline Revista Brasileira de Alergia e Imunologia ${ }^{1}$ & 23.4 & 91.2 & 8.8 & 95.6 \\
\hline Revista Brasileira de Anestesiologia ${ }^{2}$ & 27.0 & 89.2 & 10.8 & 99.1 \\
\hline Revista Brasileira de Biologia ${ }^{2}$ & 24.0 & 75.3 & 24.7 & 95.8 \\
\hline Revista Brasileira de Cancerologia ${ }^{1}$ & 16.6 & 77.9 & 22.1 & 96.6 \\
\hline Revista Brasileira de Cirurgia Cardiovascular ${ }^{2}$ & 20.3 & 91.5 & 8.5 & 97.8 \\
\hline Revista Brasileira de Educação Médica 1 & 9.7 & 55.2 & 44.9 & 61.7 \\
\hline Revista Brasileira de Ginecologia e Obstetrícia² & 19.3 & 95.3 & 4.7 & 100.0 \\
\hline Revista Brasileira de Hematologia e Hemoterapia ${ }^{2}$ & 25.6 & 87.6 & 12.5 & 99.9 \\
\hline Revista Brasileira de Medicina ${ }^{1}$ & 10.0 & 74.2 & 25.8 & 100.0 \\
\hline Revista Brasileira de Medicina do Esporte ${ }^{2}$ & 34.3 & 96.7 & 3.3 & 100.0 \\
\hline Revista Brasileira de Otorrinolaringologia ${ }^{2}$ & 15.0 & 91.5 & 8.5 & 93.6 \\
\hline Revista Brasileira de Psiquiatria ${ }^{3}$ & 23.2 & 92.1 & 7.9 & 99.6 \\
\hline Revista Brasileira de Saúde Materno Infantil ${ }^{2}$ & 30.9 & 74.6 & 25.4 & 99.3 \\
\hline Revista da Associação Médica Brasileira ${ }^{3}$ & 19.7 & 89.9 & 10.1 & 94.6 \\
\hline Revista de Ciências Médicas ${ }^{1}$ & 13.5 & 76.6 & 23.4 & 96.5 \\
\hline Revista de Psiquiatria Clínica² & 23.0 & 94.9 & 5.1 & 94.0 \\
\hline Revista de Saúde Pública ${ }^{4}$ & 14.5 & 67.3 & 32.8 & 87.5 \\
\hline Revista do Hospital das Clínicas (São Paulo) ${ }^{3}$ & 21.0 & 93.0 & 7.0 & 95.5 \\
\hline Revista do Instituto de Medicina Tropical de São Paulo ${ }^{3}$ & 22.2 & 85.9 & 14.1 & 92.2 \\
\hline Revista Médica de Minas Gerais ${ }^{1}$ & 11.2 & 45.4 & 54.6 & 76.7 \\
\hline São Paulo Medical Journal ${ }^{3}$ & 19.6 & 92.1 & 7.9 & 96.6 \\
\hline Mean \pm SD & $20.9 \pm 6.9$ & $86.0 \pm 11.2$ & $14.0 \pm 11.2$ & $94.4 \pm 7.0$ \\
\hline Median & 20.3 & 89.9 & 10.1 & 95.7 \\
\hline
\end{tabular}

The number of citations/article and the percentage of Brazilian and non-Brazilian citations and of citations from ISI-Thompson-indexed journals are presented.

1 Journals indexed only in LILACS; ${ }^{2}$ Journals indexed in LILACS + SciELO; 3 Journals indexed in LILACS + SciELO + MEDLINE; ${ }^{4}$ Journals indexed in LILACS + SciELO + MEDLINE + ISI-Thompson. 
for the data reported in the present paper. Whatever the reason, we may state that, at least in medical publications, the Brazilian authors preferentially cite papers published in English, and mainly from the North American literature.

It is difficult, of course, to separate research from local problems, but science is an international enterprise and, although being a socially conditioned activity in this context, it should be universal and independent of the language in which it is expressed.

When a physician or a biomedical researcher cites a journal article, this fact indicates that the cited paper has influenced him or her in some manner and reflects the credibility and quality acceptance of that journal by the scientific community (7).
In any case, the publication of a paper by a Latin American medical scientist in a journal with high credibility makes him proud of his science, even if that article is not cited by anybody. It has been said that a strong or seminal paper submitted to a minor journal might not receive the scientific recognition it deserves. Likewise, a weak article published in a major journal will probably receive more recognition than it deserves (8). It can also be said that evaluation of journals is a formidable but necessary task considering the wide range of choices available. Limited funding and space, as well as other factors, dictate the need for a carefully planned strategy of journal selection. There is evidence that scientific quality is found beyond the articles indexed by internation-

Table 2. Citation pattern of Brazilian journals as a function of the indexing services that cover them.

\begin{tabular}{|c|c|c|c|c|}
\hline & $\begin{array}{l}\text { Mean number } \\
\text { of citations/article }\end{array}$ & $\begin{array}{l}\text { Percentage of non- } \\
\text { Brazilian journal } \\
\text { citations }\end{array}$ & $\begin{array}{l}\text { Percentage of } \\
\text { Brazilian journal } \\
\text { citations }\end{array}$ & $\begin{array}{l}\text { Percentage of } \\
\text { non-Brazilian } \\
\text { journals that are } \\
\text { indexed in ISI }\end{array}$ \\
\hline $\begin{array}{l}\text { Only in LILACS } \\
\qquad(N=10)\end{array}$ & $\begin{array}{c}22.88 \pm 6.84 \\
(15.03)\end{array}$ & $\begin{array}{c}85.46 \pm 13.90 \\
(83.54)\end{array}$ & $\begin{array}{c}14.55 \pm 13.90 \\
(16.47)\end{array}$ & $\begin{array}{c}91.52 \pm 6.21 \\
(96.13)\end{array}$ \\
\hline $\begin{array}{l}\text { LILACS + SciELO } \\
\qquad(\mathrm{N}=19)\end{array}$ & $\begin{array}{c}24.38 \pm 8.05 \\
(20.04)\end{array}$ & $\begin{array}{c}89.82 \pm 4.49 \\
(89.68)\end{array}$ & $\begin{array}{c}10.18 \pm 4.49 \\
(10.32)\end{array}$ & $\begin{array}{c}94.62 \pm 2.89 \\
(96.61)\end{array}$ \\
\hline $\begin{array}{l}\text { LILACS + SciELO + } \\
\text { MEDLINE }(N=10)\end{array}$ & $\begin{array}{c}21.11 \pm 5.50 \\
(21.58)\end{array}$ & $\begin{array}{c}87.82 \pm 8.20 \\
(91.86)\end{array}$ & $\begin{array}{c}12.18 \pm 8.20 \\
(8.15)\end{array}$ & $\begin{array}{c}96.50 \pm 3.63 \\
(94.63)\end{array}$ \\
\hline $\begin{array}{l}\text { LILACS + SCIELO + } \\
\text { MEDLINE + ISI }(N=4)\end{array}$ & $\begin{array}{c}16.17 \pm 6.4 \\
(21.02)\end{array}$ & $\begin{array}{c}79.06 \pm 17.10 \\
(88.03)\end{array}$ & $\begin{array}{c}20.94 \pm 17.10 \\
(11.98)\end{array}$ & $\begin{array}{c}91.36 \pm 12.34 \\
(94.46)\end{array}$ \\
\hline
\end{tabular}

Data are reported as means \pm SD and the numbers in parentheses indicate the median. The journals were grouped into four categories depending on their indexation sites.

Table 3. Languages in which Brazilian medical journals are published.

\begin{tabular}{lcccc}
\hline & $\begin{array}{c}\text { Journals } \\
\text { published } \\
\text { only in Portuguese }\end{array}$ & $\begin{array}{c}\text { Journals } \\
\text { published } \\
\text { only in English }\end{array}$ & $\begin{array}{c}\text { Journals published } \\
\text { in English and } \\
\text { Portuguese }\end{array}$ & $\begin{array}{c}\text { Journals published } \\
\text { in English, Portuguese } \\
\text { and Spanish }\end{array}$ \\
\hline Only in LILACS $(\mathrm{N}=10)$ & 10 & 0 & 0 & 0 \\
LILACS + SciELO $(\mathrm{N}=19)$ & 9 & 3 & 6 & 1 \\
LILACS + SciELO + & 2 & 5 & 2 & 1 \\
MEDLINE $(\mathrm{N}=10)$ & 0 & 2 & 2 & 0 \\
LILACS + SciELO + \\
MEDLINE + ISI $(\mathrm{N}=4)$
\end{tabular}


ally recognized reference databases (6). However, to achieve the level of excellence needed to publish in these databases the investigators face many barriers, language being one of them. This might explain why, even in papers written in Portuguese with no international penetration, the references are predominantly from the foreign literature, since the recognition of high quality journals is widespread even among the scientists unable to achieve the required quality to have their paper published in a recognized international database journal. In spite of this, the number of Brazilian health-related scientific publications in international journals with high impact in the specific areas is increasing and has shown a clear upward trend, more than 9-fold, in the 10-year period from 1992 to 2001 (9). This indicates that good science is publishable in good journals and also that good papers are read by most investigators, even by those who predominantly publish articles in Brazilian journals without international circulation.

This fact is barely influenced by which database the journal is indexed in. The Brazilian journals indexed in LILACS and writ- ten in Portuguese, indexed in SciELO and written either in Portuguese or English, indexed in MEDLINE or indexed in ISIThompson, only marginally differ in their pattern of citations, as shown in Table 2. It should be pointed out that, even if the scientific publications of Brazilian researchers are receiving significant international recognition, the acceptance of the Portuguese language as a communication vehicle on the international scenario is still highly restricted.

Even knowing that the most important thing about a paper is its reproducibility and that the real peer review only starts when it is published (9), the pattern of Brazilian-edited medical journal citations shows a predominance of articles published in English, with a clear preference for journals from the ISIThompson database.

The results of the present study show that authors publishing in Brazilian Medical Journals preferentially cite the foreign scientific literature. The language used in the text of Brazilian-edited journals (Portuguese or English), as well as the database in which the journals are indexed, have little influence on the pattern of citations of Brazilian authors.

\section{References}

1. Bracho-Riquelme RL, Pescador-Salas N, Reyes-Romero MA. Bibliometric repercussions of adopting English as the sole language for publication. Rev Invest Clin 1997; 49: 369-372.

2. National Center for Biotechnology Information. 2006. http://www. ncbi.nlm.nih.gov/entrez/query.fcgi?db.

3. Gura T. Peer review, unmasked. Nature 2002; 416: 258-260.

4. Coura JR, Willcox LC. Impact factor, scientific production and quality of Brazilian medical journals. Mem Inst Oswaldo Cruz 2003; 98 : 293-297.

5. Page J, Heller RF, Kinlay S, Lim LL, Qian W, Suping Z, et al. Attitudes of developing world physicians to where medical research is performed and reported. BMC Public Health 2003; 3: 6.

6. Dinkel A, Berth $\mathrm{H}$, Borkenhagen A, Brahler E. On raising the interna- tional dissemination of German research: Does changing publication language to English attract foreign authors to publish in a German basic psychology research journal? Exp Psychol 2004; 51 : 319-328.

7. Adam D, Knight J. Journals under pressure: publish, and be damned. Nature 2002; 419: 772-776.

8. Callaham M, Wears RL, Weber E. Journal prestige, publication bias, and other characteristics associated with citation of published studies in peer-reviewed journals. JAMA 2002; 287: 2847-2850.

9. Paraje G, Sadana R, Karam G. Public health. Increasing international gaps in health-related publications. Science 2005; 308: 959960. 